\title{
A New Era for The Sea
}

\section{by K. H. Brink ${ }^{1}$ and James J. McCarthy ${ }^{2}$}

Now in its 80th year of publication, Journal of Marine Research has always striven to serve the oceanographic community by publishing papers vital to the marine research in the long and rich tradition of the Sears Foundation for Marine Research. As such, with this special issue we bring into the fold The Sea, the long-standing highly respected series that provides a continuing, comprehensive, and timely synthesis of the state of knowledge of ocean science.

The Sea is now entering a new phase of its storied existence. Although the series has been successful as a collection of episodically published print monographs (which are not discoverable by the citation services), growing demand for an online presence and recognition has led the editors to revise its publication model radically.

Beginning with the next volume in the series, The Sea will appear as occasional special issues of the Journal of Marine Research. This means that individual contributions to The Sea will be published online as part of an established scientific journal, both visible to online citation and abstract services, and available in easily distributable electronic format. Print copies of this and future volumes in the series will be made available for purchase as print-on-demand supplements to the Journal of Marine Research.

We invite you to follow the progress of the revitalized The Sea by visiting our website, and to share your comments with any member of the series editorial board.

We are proud to begin this new era for The Sea with Volume 17 in the series, "The Science of Ocean Prediction," in this first of two special issues of the Journal of Marine Research. Volume editors Nadia Pinardi, Pierre F. J. Lermusiaux, Kenneth H. Brink and Ruth H. Preller have worked to make this next volume current, comprehensive and thought-provoking, with a focus on underlying concepts that ought to allow this work to remain relevant for years despite its rapidly advancing subject. The volume's development has been greatly aided by the editorial advisory board of Gary B. Brassington, Sissy Iona, Pierre-Yves Le Traon, Guimei Liu, Art Miller and Ralph F. Milliff. The efforts of all the engaged scientists, as editors and authors, are deeply appreciated.

1. Woods Hole Oceanographic Institution.

2. Museum of Comparative Zoology, Harvard University. 